\title{
The Social Construction of Data: Methodological Problems of Investigating Learning in the Zone of Proximal Development
}

\author{
Peter Smagorinsky \\ University of Oklahoma
}

\begin{abstract}
Educational researchers have traditionally drawn on procedures and metaphors from the hard sciences to guide their thinking about methodological issues. One frequently invoked metaphor is that of the purity of data, which a researcher can contaminate through the process of investigation. This article questions the appropriateness of the purity metaphor, using a perspective provided by Vygotsky's notion of the zone of proximal development (ZPD) and its emphasis on a genetic method in which development is mediated by cultural tools and signs. Methodological problems emerging from this conception of the ZPD-including problems of defining research, identifying an appropriate unit of analysis, considering the relationship between evidence and telos (an optimal sense of development), and accounting for the mediational role of assessment-are reviewed. Finally, the work of Luria (1976) is examined from the neo-Vygotskian perspective developed in this article.
\end{abstract}

Researchers in education, psychology, and related fields have historically been concerned with the extent to which the research methods they employ affect the emergence of the data they collect and analyze. Many publications have cautioned researchers about the perils of the Hawthorne effect (Adair, Sharpe, \& Huynh, 1989) and the Heisenberg uncertainty principle (McKerrow \& McKerrow, 1991). The operative metaphors that have characterized researchers' implication in the data collection process have often stressed the notion of the purity of data. Researchers "intrude" through their media and procedures, or worse, they "contaminate" the data by introducing some foreign body into an otherwise sterile field. The assumption behind these metaphors of purity is that the researcher must not adulterate the social world in which the data exist, but rather must work in the manner of the biologist who observes the life in a petri dish without using instruments that might disrupt the self-contained, natural biological processes unfolding in that microsystem. The assumption that data are pure implies that researchers must endeavor strongly to observe and capture the activity in a research site without disrupting the "natural" course of human development taking place therein. Data collection procedures, according to this metaphor, must not "intrude" in such a way as to affect this insular natural process, but must instead be neutral and inconspicuous in order to capture data in their immaculate form.

However, sociocultural theory emerging from the work of Vygotsky (1978, 1934/1987; Vygotsky \& Luria, 1993) raises issues that challenge the appropriate- 


\section{Smagorinsky}

ness of the purity metaphor in social science research. Vygotsky's developmental theory and its complex implications stress the inherent social nature of all human activity. From a neo-Vygotskian perspective, data are social constructs developed through the relationship of researcher, research participants, research context (including its historical antecedents), and the means of data collection.

A neo-Vygotskian perspective resonates with other Marxist views that have undergirded critiques of education and psychology and their research traditions in recent years. Long before Vygotsky became a common reference outside the former Soviet Union, Berger and Luckman (1966) described the social construction of reality and its consequences for human institutions, thinking, and activity. More recentiy, poststructuralists such as Brodkey (1992) and McLaren (1992) have engaged in "critical literacy," the examination of the political, cultural, and economic assumptions behind historically situated, culturally shaped, and thus subjectively constructed definitions of literacy. With issues of diversity and equity facing education at all levels, neo-Marxist perspectives have become common in accounts of teaching and learning emerging from the professoriat, allowing scholarly critics to examine the assumptions behind educational structures and traditions and to explicate the ways in which they represent a masculine, Eurocentric worldview (Foucault, 1972).

Vygotsky's sociocultural psychology, long suppressed in the former Soviet Union and only recently given widespread translation and attention, sits comfortably amidst these neo-Marxist views of Western culture. What distinguishes Vygotsky's perspective from other Marxist views is his genetic method, a term translated from the Russian word geneticheskii and referring to development rather than genes or genetic codes (Wertsch, 1985). Vygotsky saw development as social in origin and reliant on tools and signs for the mediation of mental processes. Whereas most neo-Marxist critiques emerge from political views of adult institutions, Vygotsky was able to provide an account of sociocultural development rooted in the very origins of thinking and speech, the mediational tool he found most prevalent in Western culture. While thus providing the basis for many of the same conclusions reached through conventional Marxist social critiques, Vygotsky's genetic analysis enabled him to ground his account of subjectivity in the socially mediated processes of psychological transformation.

In this essay, my goal is to explicate Vygotsky's notion of the development of consciousness and relate that view to the conduct of research. I will begin by reviewing the problems involved in claiming a neo-Vygotskian perspective. I will then provide an account of Vygotsky's conception of the zone of proximal development and its emphasis on a genetic method in which development is mediated by tools and signs, and the mind is thus elastic and unbounded. Included in this account is a discussion of the problem of telos-that is, an optimal sense of development that implies the path psychological growth should take. I will then review methodological problems that emerge from this conception of the zone of proximal development, including problems of defining research, identifying an appropriate unit of analysis, understanding the relationship between evidence and telos, and considering the mediational role of assessment. Then I will look at the relationship between research and teaching from the neo-Vygotskian perspective I outline. Finally, I will review the research of Vygotsky's student and collaborator A. R. Luria (1976) and offer a critique of his often-cited research on literacy 
development in remote Soviet provinces during a time of economic transformation; this critique will examine Luria's conclusions through the neo-Vygotskian lens I establish.

\section{Problems in Claiming a Neo-Vygotskian Perspective}

Speaking for Vygotsky has become a common practice in much modern scholarship on teaching and learning. This is problematic given that most non-Russians rely on translated versions of Vygotsky's works, and given that people have found different ways to appropriate what appears in the translations. From a semiotic standpoint, Vygotsky's work has become a sign to which adherents to different theoretical positions have attributed different meanings. For instance, a single text, Myshlenie i Rech': Psikhologicheskie Issledovaniya (Vygotsky, 1934), has been translated three different times under two different titles (Vygotsky, 1934/ 1962, 1934/1986, 1934/1987). Moll (1990) sees Vygotsky's work as sociohistorical psychology, whereas Wertsch (1994) argues that Vygotsky's perspective is sociocultural. The zone of proximal development (described next), according to Lave and Wenger (1991), has been interpreted in three completely different ways; additionally, it has been invoked to account for the success of theoretically incompatible pedagogical approaches, such as a whole-language approach that minimizes teacher direction (Goodman \& Goodman, 1990) and reciprocal teaching, in which "membership in the group is not democratic; the adult teacher is definitely a first among equals" (Brown \& Palincsar, 1989, p. 417). Cazden (in press), in surveying modern citations to Vygotsky, has argued that most readings of Vygotsky are "selective" and reveal more about the appropriators than about Vygotsky's psychological theories.

In claiming a neo-Vygotskian perspective, I thus engage in a social practice of knowledge construction, using my understanding of Vygotsky-mediated by my encounters with a variety of neo-Vygotskian viewpoints in conversation, print, and cyberspace - for grounding in advancing my points. My use of Vygotsky undoubtedly reflects my own approach to theory building-my own world of meaning that informs my attribution of meaning to the signs provided by translations of Vygotsky's work-as I consider problems involved in conducting research.

\section{The Zone of Proximal Development and the Unlimited Mind}

\section{The Zone of Proximal Development, the Genetic Method, and Telos}

Key to Vygotsky's genetic account of development is his postulation of the zone of proximal development (ZPD), which is typically thought of as each person's range of potential for learning, where that learning is culturally shaped by the social environment in which it takes place. The ZPD brings into play the three themes that Wertsch (1985) finds central in Vygotsky's theoretical framework: a reliance on a genetic (developmental) method, an assumption of the social origins of consciousness, and a claim that mental processes are mediated by tools and signs.

An account of mediation is central to any discussion of tool use. To Vygotsky, self-regulation through the mediation of semiotic signs characterizes psychological growth. Signs therefore mediate a person's internalization and communication 


\section{Smagorinsky}

of cultural values. A tool such as speech can create signs such as words that serve to structure the developmental environment of an individual; through this structuring, signs potentially serve as tools for regulation and mediation. The cultural values of a people are represented in the sign systems they use to order their activity and relationships. Vygotsky himself, for instance, came from a middleclass European Jewish family and thus recognized (a) speech-generated signs as the primary mediational means of his culture and (b) "scientific" or decontextualized thinking as the highest form of concept development allowed by this sign system (Vygotsky, 1934/1987). In cultures that rely on speech for regulation, speech genres, or ordered systems for using linguistic signs, mediate the ways in which people learn to think in particular social settings (Wertsch, 1991).

Other sign systems can mediate thinking and activity, as well. Semiotic studies have examined the roles of dance (Hanna, 1987; Smagorinsky \& Coppock, in press-a), art (Smagorinsky \& Coppock, 1994), physical space (de Certeau, 1985), color (Eco, 1985), and other types of signs in providing mediation and enabling self-regulation among members of various cultures (John-Steiner, 1987, 1995). The mediational process is predicated on the ways in which people invest signs with meaning (Wertsch, 1985), particularly the ways in which members of a culture structure society according to shared meanings for signs (Cohen, 1989).

This discussion so far has assumed that purposeful, tool-mediated activity enables development. The idea of development, however, is problematic in that it suggests some sense of telos, or path towards a desired, positive, or optimal sense of completion. It therefore raises the question, development towards what? (Wertsch, 1995). For instance, many neo-Vygotskian researchers find Piaget's sense of telos to be culture-specific and thus parochial in its view of human potential. Hundeide (1985) questions the universality of the cognitive stages described by Piaget and the specific optimal developmental outcome they lead to. He says,

When we study other cultures with different institutions and episodic structuring of reality, we may find that the definition required for the proper execution of certain mental operations that are of interest to us are outside the episodic repertoire of that culture. In such cases, an orthodox Piagetian diagnostician runs the risk of diagnosing an entire culture as "preoperational." (pp. 310-311)

From a neo-Vygotskian perspective, then, a sense of telos may be grounded in unexamined cultural assumptions about the ways in which people have historically developed in particular societies. That sense of telos may be inappropriate for judging people from other cultures, as frequently happens when members of technologically advanced societies encounter members of technologically limited societies (e.g., the characterization of Native Americans as "savages" by European explorers).

In addition to different views of a telos of general developmental processes, questions abound concerning more specific paths of development, even within societies whose predominant sign systems promote regulation through similar general processes such as Piagetian stages of cognitive development. Many cultures lead people to internalize "higher" or sociocultural mental processes that, from other perspectives, are not "positive" or optimal. Urban youths participate in street gang activities, for instance, and internalize codes of behavior that are 
antithetical to civil law. A genocidal society such as Nazi Germany might provide signs and tools that lead its citizens to believe in and participate in the extermination of other groups of people, a practice labeled by members of other cultures as war crimes and atrocities. Wells (1995) has attempted to solve the developmental conundrum by arguing that development can be considered a function of a learner's immediate sense of an activity's worth, regardless of other judgments. Children whose environments teach them anti-Semitism, then, can be said to be "developing" towards a positive end point within the bounds of their cultural values, even though members of other cultures might find the developmental path to be negative and pernicious.

In stressing the idea of telos, I should emphasize that a person is not limited to a single developmental focus, but can be developing in several ways at once. Tulviste's (1991) principle of heterogeneity is informative on this point. In his account of activity theory, Tulviste maintains that an environment, or overlapping social networks, can present a learner with a variety of types of problems to solve, thus allowing individuals to develop a number of frameworks for thinking. Development can thus take several directions simultaneously; a person can learn the value of care from a personal relationship and aggression from involvement in sports. The heterogeneity principle helps to account for the complexity of human life and the many roles that people play in their daily relations.

The extent to which a person internalizes the values of any cultural way of knowing depends on his or her degree of consonance with the cultural tools that mediate development. Tools enable meaning construction when they are sanctioned by the cultural environment of learning, are recognized by the learner as tools, and are used volitionally by the learner (Smagorinsky, 1995; Smagorinsky \& Coppock, 1994, in press-a, in press-b). Children who are abducted and raised in a child pornography industry against their will would not, in this conception, be in a state of development. Even though they are immersed in a cultural value system that provides them with tools and signs for mediating mental activity towards a certain optimal end point, they presumably do not agree with that end point, do not act volitionally, do not value the cultural tools provided to them, and thus resist the effort to shape their higher mental processes. The conception of development I am presenting assumes the learner's acceptance of the value system underlying the semiotic structure of the environment and the need for intersubjectivity with the sense of meaning communicated through the signs that order thinking and activity. This sense of consonance includes a mutual agreement not only on the meaning of signs, but on the ways in which tools are used to produce them. Such congruent tool use might require intersubjectivity in a variety of social relationships, including the participant structure of activity (Philips, 1972) and the ways in which community members share an understanding of task and tool use in the process of appropriation (Leont'ev, 1981; Newman, Griffin, \& Cole, 1989).

\section{The ZPD's Protean Character}

Vygotsky (1978) illustrates the ZPD with the example of a child advancing in development through the assistance of an adult or a more capable peer. The child, he says, can perform at a developmentally more advanced level when assisted than when acting alone, and this difference in level of performance suggests that a 


\section{Smagorinsky}

learner has a range of potential rather than some fixed state of ability. Learners ultimately internalize the knowledge transacted through assisted performance. That knowledge passes from the intermental plane (between two or more people) to the intramental plane (the learner's appropriation of socially learned knowledge); that is, learners appropriate cultural knowledge through a dialectic relationship with more experienced members of their society.

The ZPD has powerful methodological significance for educational researchers. The implications stem from a conception of the extent and character of the zone itself-in particular, the way the conceptualization of the ZPD suggests that the mind is not fixed in its capacity but rather provides a range of potential. The mind, therefore, is both elastic in that cognitive growth may take different directions depending on the sociocultural environment in which it occurs, and unbounded in terms of its extent and potential for growth.

The elastic mind. The mind's elasticity is reflected in Vygotsky's notion of "higher" or sociocultural mental processes. In this view, the type of thinking internalized depends on the historical and cultural knowledge and practices endemic to the surrounding adult community and the resultant form that adult assistance takes. In other words, "higher" mental processes have no specific operations, but embody the most highly evolved form of the ways of thinking that a particular culture has developed over the years and passed down from adult to child. Tulviste (1991) has argued that thinking develops according to the types of problems an environment presents to learners in a culture to solve. Through activity in the environment, people develop higher mental processes that are appropriate to addressing culture-specific needs. Hundeide's (1985) critique of Piaget illustrates the problems that can occur when one developmental path is criticized according to the structure of another. In this conception of the development of thinking, "universal" operations are possible only insofar as universal human experiences allow for the development of universal ways of knowing. Even in the case of universal human needs such as sex drive and hunger, conceptions of appropriate practices are rooted in cultural values and vary from group to group.

The unbounded mind. Just as crucial from a methodological standpoint is the second set of potentials, the unboundedness of the mind. The mind is unbounded in two ways, one related to an individual's capacity for development and one related to the role of tools in mediating development.

As is frequently noted in accounts of the ZPD, the mind is theoretically limitless in its potential for cognitive growth (Cazden, 1979). The zone is a range of ability, and its upper reaches are continually in a state of evolution. Development consists of using socially mediated assistance to move towards the higher levels of the range, which is itself always developing into a new and more complex state.

The other important implication of the unbounded mind, one with profound ramifications for research methodology, concerns the limitlessness of the mind in terms of its physical location due to the reliance of thinking on tools and signs. Most accounts of the human mind have it locked within the skull; Descartes, Rousseau, Freud, and others have posited a mind/matter dichotomy where the mind exists in a "natural" state and loses its purity through association with society, even becoming corrupt through social transactions in the views of Rousseau and Freud. In a Piagetian conception, according to Newman et al. (1989), "direct 
instruction will actually inhibit the child's understandings if instruction gets in the way of the child's own exploration" (p. 92).

From the neo-Vygotskian perspective I am taking, unadulterated development could only take place in vacuo, a state not possible in human society. Vygotsky's distinction between biological (lower) and socioculturally mediated (higher) mental processes provides the framework for a view of development in which biological factors provide the range of cognitive potential of a learner's ZPD (just described as a learner's capacity for development), which then takes shapebecomes the individual's "higher" mental processes-through the learner's use of mediational tools, which he or she uses to internalize the historical cultural means of mentation that characterize mental adaptation and transformation in the surrounding social milieu. Vygotsky's insistence on the inherent social nature of development challenges the mind/matter dichotomy (see, for instance, Rogoff's [1990] critique of Piaget) and raises questions about the extent to which "natural" development is possible (cf. Smagorinsky \& Whiting, 1995). If development is socially mediated, then commerce with other humans does not contaminate the natural mind but rather provides the tools and signs through which the inherently social mind develops according to particular cultural codes.

Psychological tools provide the means through which an individual internalizes the higher mental processes central to social transactions in particular cultures. Wertsch's (1985) position that goal-directed, tool-mediated activity (as opposed to Vygotsky's postulation of word meaning) should be the unit of analysis for psychological study provides the basis for the notion of the ZPD that I will elaborate in this essay. This view emphasizes sociocultural transformation, with the environment of learning providing mediational tools that learners may use to internalize the ways of thinking central to participation in the cultural world around them (Lave \& Wenger, 1991). These tools take on value according to the types of problems presented to societies by their environments, and the ways in which members of the societies have learned to solve those problems (Tulviste, 1991). Mediational tools not only abet the development of higher mental processes, but are themselves a fundamental part of those processes. Social transactions are necessarily mediated by some sort of cultural tool, such as speech that follows specific social conventions. These cultural or psychological tools themselves are central to human thought and development; they are the means through which children internalize cultural knowledge and exercise their own mentation. Because these tools are central to thinking and are social in origin, they are necessarily part of culturally-rooted cognitive development.

In this conception the ZPD is not restricted to the internal symbol systems of the individual alone, but includes the tools in a social context through which learners mediate thought and activity. Wertsch (1991) asserts that the mind "extends beyond the skin" (p. 14); that is, it is socially distributed and is a function of activity involving cultural tools. From this perspective, the mind is unlimited in the sense that its development is inseparable from the tools of mediation, which themselves are often corporeal things (e.g., computers, paint brushes) that extend out into the material world. The means of mediation can also be invisible yet powerfully influential in shaping thought and communication, such as the speech genres that govern discourse in specific sociocultural settings (Marshall, Smagorinsky, \& Smith, 1995; Smagorinsky \& Fly, 1993; Wertsch, 1991). Finally, 


\section{Smagorinsky}

the tools of mediation might be so embedded in daily life-for instance, a speedometer or an appointment book-that people do not notice them as tools (Pea, 1993).

These tools have no inherent value and use, but take on meaning as tools with specific values and uses through the historical cultural functions that members of a society have found for and attributed to them. Psychological tools thus link individual minds to other minds, both those that are immediate and contemporary and those that have provided the cultural antecedents through which mediational tools accrue value and assume meaning. The mind is thus spatially unbounded in that through the tools of mediation, it extends out and is connected to the social and cultural world in which it develops. From a semiotic standpoint, the signs that a culture establishes to order its world require tools for creation and interpretation and, thus, cultural tools and semiotic signs link people across generations as well as to their contemporaries.

\section{Methodological Problems}

\section{Defining Research}

In this section I will examine research as a social construct. Modern social science research is in a period of reexamination, with researchers of different paradigms often in conflict over which approach provides the truer picture of learning and developmental processes. I will not attempt to review all of the competing approaches, which seem myriad and have been debated in journals (e.g., Berliner, 1992) and books for some time now. My effort, very broadly speaking, will be to discuss empirical research, which I view as encompassing a broad range of methodologies, including those typically characterized as "qualitative" and "quantitative." Regardless of whether a methodology relies on numeric representations of data or verbal "thick descriptions" of life (Geertz, 1973), empirical research makes claims based on data and is presented in some form of argument. Behrens and Smith (in press) have identified five features of data and their use in research, regardless of how they are collected and analyzed. According to Behrens and Smith, the act of analysis is a construction of the researcher, all "data" are analyzed in terms of the symbols (usually words or numbers) that represent them, the process of analysis is social, the goal of analysis is to reduce complex data to a manageable summary, and the results of data analysis are provisional and contestable. My effort here is to avoid the polemics that often characterize methodological disputes and take a pluralistic and inclusive view of research.

Empirical research itself is a social construction, being developed and practiced primarily in Western cultures that value the development of "scientific" thinking (Vygotsky, 1934/1987); that is, the development of formal concepts that are abstracted from the immediate context of their usage and used to develop formal rules for broad application. Empirical research thus strives to generalize evidence found in the contexts of particular studies, and to derive principles for application to other similar situations. Even research that focuses on the particular can offer general principles, such as Smagorinsky and Coppock's (1994, in press-a, in press-b) argument that the unique acts of meaning construction found in the artistic composing processes of case-study students suggest the need to reconsider 
the uniformity in typical school assessment.

As cultural practice, research serves both to represent values and to shape them; research is thus both tool and sign. Bazerman's (1988) extended analysis of the genre and activity of the experimental article in science reveals the ways in which research is both tool and sign for regulating cultural behavior (cf. McCloskey's [1985] analysis of the rhetoric of economics, which, he argues, relies on "scientistic" language using "hard" empirical data to make political arguments). Bazerman finds that the genre of the scientific article has evolved over time along with changes in the field, and thus both represents and regulates activity simultaneously. The Publication Manual of the American Psychological Association (American Psychological Association, 1983), he argues, "embodies behaviorist assumptions about authors, readers, the subjects investigated, and knowledge itself. The prescribed style grants all the participants exactly the role they should have in a behaviorist universe" (p. 259). Bazerman's critique is aimed more at examining the consequences of the American Psychological Association format than at condemning behaviorist viewpoints (C. Bazerman, personal communication, March 10, 1995). Taking a more pointed view of rhetorical effects, McCarthy and Gerring (1994) argue that the revision of the most important book in the mental health profession, the Diagnostic and Statistical Manual of Mental Disorders (DSM-IV; American Psychiatric Association, 1994), was an effort not so much to change the text as to achieve social and political ends: establishing the superiority of the biomedical model of mental disorder, maintaining psychiatry's dominance over psychology in the mental health field, and enhancing psychiatry's prestige relative to other medical fields.

The idea of empirical research, therefore, is consistent with the "essayist" literacy (Olson, 1977) that dominates Western discourse and serves as a sign and tool to regulate academic thinking. The argumentative form provides a template for making claims based on data, regardless of how the data are collected, analyzed, or presented. It also represents the rational approach to problem solving that characterizes the dominant institutions of Western culture.

\section{Unit of Analysis}

Because development involves goal-directed, tool-mediated activity, the unit of analysis for psychological study cannot be an artifact of learning that presumably represents a crystallized, fully formed state of development independent of the artifact's cultural significance and the means through which the learner has appropriated an understanding of how to produce it. Vygotsky (1978) criticized psychological research that involves training participants to complete a task and then conducting formal data collection only during an activity that follows the training. To Vygotsky, the training sessions are the most theoretically compelling periods of activity that take place during psychological research, in that they represent the occasions during which learning occurs. In the training sessions, the participants learn how to use the mediational tools in what the researcher believes to be the most appropriate manner, a process that involves the learner's development through the ZPD; to use Leont'ev's (1981) term, the process of appropriation often takes place during training. To Vygotsky, this process is of infinitely greater theoretical importance than the fully appropriated knowledge that is often studied during psychological research, or, conversely, the participant's lack of appropria- 


\section{Smagorinsky}

tion, which leads to "poor" performance and therefore deficit-driven judgments of a participant's cognitive abilities. By focusing on the idea that data collection captures the participant's "ability" instead of his or her capacity for employing the researcher's mediational tools for development through the ZPD, such studies misrepresent the developmental process and the learner's relationship with the tools of mediation.

The appropriate unit of analysis of psychological study also cannot isolate variables that are inseparably linked in the developmental process, although both in Vygotsky's time and in current psychological research, learning has often been studied through the breakdown of a whole process into its parts (e.g., the "cognitive skills" focus of much research in reading and other fields). Efforts to account for the whole of a process in terms of an analysis of its discrete parts, therefore, will lead down the slippery slope, because rather than being a collection of discrete parts, "the separate functions are linked with one another in activity" (Vygotsky, 1934/1987, p. 43). That is, they make up a unit of analysis "that possesses all the basic characteristics of the whole" (p. 46).

Similarly, researchers of psychological processes cannot separate the changes in consciousness that are usually the objects of psychological study from the goaldirected, tool-mediated activity through which the changes take place. Because tool use is fundamental to changes in consciousness such as the concept development central to Vygotsky's (1934/1987) notion of cognitive growth, researchers need to understand the relationship among the mediational tools, their historical cultural uses within the learner's community, their means of employment in the learning (and research) environment, the intersubjectivity between the learner's understanding of the learning task and the evaluator's (teacher's or researcher's) understanding of the task, and other factors that make up the interrelated social environment of learning.

\section{Telos and Evidence}

As Bazerman (1988) points out, the scientific article relies on a notion of argumentation that is based on the use of some sort of evidence to support a claim. While this very argumentative structure itself represents a socially constructed process and form of thinking, so does the problem of what counts as data, and the question of what a set of data counts as evidence for. Once again, the problem of telos in development arises. If something is believed to count as data, and if those data serve as evidence to support a claim about the extent of human development found in human behavior, then there is a necessary relationship between (a) assumptions about the optimal end point of development and (b) assumptions about the data that serve as evidence of progress toward that end point.

Any assessment procedure or instrument carries with it a sense of telos; that is, it embodies the researcher's sense of an appropriate developmental path for people to follow, and produces data that identify people's progress or achievement according to the direction of that path. McCarthy and Gerring's (1994) account of the revision of $D S M-I V$ illustrates this phenomenon well. In the biomedical model that undergirds the revised text,

mental disorders are understood, like physical diseases, as discrete entities, generic across cultures, which are clearly bounded from each other and from 
normal conditions. The task of researchers in the biomedical model is to see patients not as individuals but as members of populations grouped according to observable symptoms. (p. 150)

Evidence of the presence of such disorders comes in the form of a patient's proximity in diagnostic tests to norms in large populations, such as the agreement among patients on the identification of the images in a Rorschach test.

Such a model is distinct in orientation from other approaches to understanding anomalous psychic conditions and behavior, such as Jung's psychoanalytic methods "which understand mental disorder according to theories of intrapsychic workings and which focus on individual life stories rather than on patient populations" (McCarthy \& Gerring, 1994, p. 151). McCarthy and Gerring argue that the competing models are not only at odds in their assumptions about the sources of mental disorder (itself a socially constructed notion), the elicitation procedures for gathering data, the material substance of data, and ways of analyzing data, but are "competing" in the very real sense that establishing the authority of a particular method of treatment has material benefits for its practitioners: prestige, influence, and financial gain.

A sense of telos is thus closely related to the notion of what constitutes data and evidence, and a notion of appropriate methods for collecting data. Data collection procedures imply a belief in a particular developmental end point and, additionally, can serve to establish the authority of the researcher. According to the work of Bazerman (1988), McCarthy and Gerring (1994), and others, the scientific model that dominates Western research and commands the greatest resources and attention does not produce objective data to demonstrate advanced development, but rather produces culturally-shaped evidence of development towards a specific end point.

Tulviste's (1991) heterogeneity principle serves as a reminder at this point that a researcher may hold several senses of telos simultaneously. For example, a researcher can regard both autonomy and a cooperative spirit as optimal end points for human development. Thus, data collection does not necessarily serve narrow purposes but can include evidence for different ways of knowing, as is often found in complex ethnographic studies.

\section{The Mediational Role of Assessment}

The social character of development becomes crucially important when researchers undertake the study of learning. When researchers enter a sociocultural setting to conduct research on developmental processes, they become part of that setting and thus become mediating factors in the very learning they purport to document. However, rather than "contaminating" the research environment, they become additional mediational means in a learner's development. Researchers provide mediation even when the learner does not personally interact with the researcher but instead has learning measured through the mediation of some instructional intervention and assessment vehicle. Such mediational means are not culturally neutral, but rather are replete with cultural values, and thus represent cognition that is socially distributed (Salomon, 1993).

Empirical researchers, often with an eye on the Heisenberg uncertainty principle, have typically been concerned with minimizing the researcher's observa- 


\section{Smagorinsky}

tional effects upon the performance of the research participants. Yet the conception of the ZPD I have outlined suggests that this concern is misguided, because "avoiding" mediation is not possible when research is inherently mediational. The work of Moll and Greenberg (1990) raises questions about the objectivity of conventional assessment and points to the likelihood that all means of data elicitation embody a culturally biased sense of telos that is reflected in both data collection procedures and the uses of evidence in argumentation.

Moll and Greenberg (1990) investigated the learning of Southwestern Mexican American students both in school and in their home community. Concerned by the historically disproportionate failure of Latino students in U.S. schools, the researchers endeavored to identify its source. Though their failure had primarily been attributed to cognitive deficiencies, Moll and Greenberg found that in their home communities, the students engaged in a complex series of cognitive tasks, including repairing farm machinery, distilling medicine from insects, managing budgets, organizing work forces, and engaging in countless other challenging cognitive activities. In school, however, these same students were often judged by their teachers as "failing" academically, a designation that was then taken to represent their "ability" in all cognitive matters.

Taking a Vygotskian perspective, Moll and Greenberg (1990) disputed the judgments of the teachers and researchers who found these students to be cognitively deficient. Using the ZPD as the foundation for their analysis of what they believed to be an erroneous interpretation of students' academic performance, Moll and Greenberg argued that the students did not have a fixed level of "ability" that was "measured" by the neutral instruments of school assessment, but instead a range of potential that had taken a particular cultural shape through their immersion in the agricultural community in which they had been raised. Their mediational tools for demonstrating competency in their community work included such means as using speech for cooperative undertakings, using physical tools such as wrenches to configure space in their repair of machinery, and using other tools in social activity that were not central to school instruction or assessment. In school, however, students were evaluated according to isolated performance on problems involving abstract reasoning, by mediational means such as standardized tests that were culturally alien to them.

Moll and Greenberg (1990) concluded that the determination that the students were cognitively deficient was a function of culture-laden means of evaluative mediation that were more congenial to students of European American origin and middle-class backgrounds than to students of Mexican American origin and agricultural backgrounds, and that the ZPDs-which, to the researchers, included the social context of learning and the cultural tools it provided-that afforded opportunities for success in the Mexican American community did not exist in school. As a result, the students performed poorly and were judged to be deficient - a conclusion, Moll and Greenberg argued, that stemmed from a great misconception of the process of cognitive development and a nescience concerning the sociocultural character of the ZPD.

Race and ethnicity often figure prominently in cultural studies. Lee (1993), for instance, studied the discourse processes in community-based African American speech and built on them to teach reading strategies to African American students. Schultz, Florio, and Erickson (1982) studied the discourse processes of an Italian 
American dinner conversation and contrasted them with discourse patterns in the children's school. However, the problem identified by Moll and Greenberg (1990) goes beyond racial and ethnic differences. The means of mediation (such as the speech genres studied by Lee and Schultz et al.), which are always cultural, can confound learners in many different types of situations. Lave, Murtaugh, and de la Rocha's (1984) research on grocery shoppers performing mathematical operations both in the supermarket and on paper-and-pencil tests parallels Moll and Greenberg's study in interesting ways. Lave et al. accompanied shoppers and tape recorded their calculations as they sought to find the best prices on products they intended to purchase. The researchers found that the shoppers were virtually infallible in their mathematics in this situated activity. Yet these same people, when tested on identical mathematical problems presented in abstract form through the means of a paper-and-pencil test, performed quite poorly, answering fewer than half of the problems correctly. These findings were similar to those of Moll and Greenberg. The shoppers would be judged as "failures" according to the means of assessment used in school (and typically used in research on instruction and learning); and yet through a more meaningful, concrete, and appropriate means of assessment they were found to perform with uniform excellence.

These studies illustrate the hidden problems involved in conducting research, even when the researcher takes precautions to prevent "contamination." Simply by choosing a means of assessment, the researcher enters the learning environment with assumptions that a particular means of assessment is capable of determining "learning." And, as Gardner (1983) has argued, educational measurement assumes that linguistic and logical/mathematical means of assessment identify a person's "true" intellect; this assumption is made at the expense of many other types of intelligence and vehicles for developing and demonstrating it. Moll and Greenberg (1990) have pointed out that the assumption that the means of assessment are neutral can have insidious and pernicious implications for students who are not culturally attuned to the type of higher mental processes necessary for completing a given task according to the assessors' expectations. A reliance on these means of assessment erroneously assumes that a specific type of psychological mediation represents "achievement"-that is, represents progress towards a particular conception of telos-when in fact what is being measured is the cultural compatibility between the learner and the means of mediation.

The ZPD, with its implication that higher mental processes are culturally shaped rather than universal in structure, suggests that most assessment vehicles used in school and research give an advantage to those students whose higher mental processes have developed in a way that is understood and esteemed by those who create the assessment vehicles. The ZPD's developmental nature suggests that the instruments of data elicitation are never neutral but, rather, are always mediational. The ZPD has an inherently developmental and semiotic character that is instrumentally affected by the learner's appropriation and implementation of a culture's psychological tools. Data,therefore, are social constructs, in that the means of mediation are necessarily sociocultural in nature.

As argued throughout this essay, data on human development are inherently social in nature, and the invocation of the purity metaphor is therefore inappropriate in discussing investigations of learning in the ZPD. Data can only be "pure" in a sterile environment, and human development takes place in a teeming social 


\section{Smagorinsky}

milieu. To assume that learning can be separated from its social foundations is to misunderstand the nature of the ZPD; to assume that the study of learning can take place outside the bubble of the social environment of learning is to misconceptualize the role of mediation in human development and to underestimate the effects of the introduction of any research tools into the learning environment. Indeed, the tradition of referring to the research participant as a "subject" stresses the view that the participant is an "other" distinct from, and immune to, the mediating effects of the research process, a view that the neo-Vygotskian position I am taking would regard as misguided.

\section{Research as Teaching, Teaching as Research}

I have argued thus far that any research process involves an underlying sense of telos, involves the mediation of data collection methods, and involves a relationship between what counts as evidence and what is accepted as telos. Research results, I propose, are only valid when the learner is consonant with and can appropriate the mediational means of the research as useful cultural tools, and when the researcher takes into account the learner's appropriation of the research tools when finding evidence for a claim. In this conception, valid research is inherently instructional in that the congruence of learner and learning materials affords development (see Swanson-Owens \& Newell, 1994).

One way to look at this conception of research is to compare research to teaching. Though teachers and researchers conventionally have different goals (Newman et al., 1989; Wong, 1995), teaching and research are alike in fundamental ways. Teaching, like research, involves a sense of telos. In many situations, the conception of telos is overt in the identification of objectives and outcomes (Bloom, 1956; Tyler, 1949). However, even teaching approaches that are explicitly nondirectional have optimal end points in mind. For instance, Noddings (1992) says that from a Deweyan perspective, "there is no end product-no ideally educated person-but a diverse host of persons showing signs of increasing growth" (p. 165). Regardless of whether the goals are specific or broad, teaching is always purposeful, whether the purpose focuses on content area goals, process goals, personal goals, or other developmental paths. As argued earlier, what is critical is that the learner share the teacher's sense of telos so that educational activities enable development.

Teaching, like research, also involves mediation, primarily in the form of instruction and assessment. I use the term instruction here not to describe just any effort by a teacher to promote new knowledge in students, but to describe the provision of forms of mediation that involve students in problem-solving activities using appropriate cultural tools. In this view of teaching, a teacher who demands that students use tools outside their cultural repertoires for tasks that do not build on their prior problem-solving experiences is not teaching, but assigning and testing. This is not to say that teachers should require students to do only what they can already do, for such a view would negate the need for schooling. It is to say, however, that when there is little or no congruence between formal instruction and students' prior culturally fostered tool use, and when teachers make no effort to engage in a reciprocal relationship with students regarding appropriate tool use, then instruction will fail, as Moll and Greenberg (1990) found. Heath (1991) and others have pointed out that the mediational means required in school 
activities, while providing the tools necessary for success in mainstream society, need to be congruent in some way with students' prior learning experiences in order to enable them to meet scholastic goals. The problem of incongruence is most obvious in school, where attendance is mandatory rather than voluntary and where students may not believe in the goals of the institution and may experience discord with the tools through which they are expected to mediate learning. Formal learning environments such as church, scouting, adult education classes, organized sports, and other self-chosen settings more typically involve harmony between the learner's values and those of the institution.

Again like research, teaching produces evidence of a child's development towards an optimal end point, usually in the form of schoolwork that students produce, often for grades. Here, also, the notion of congruence is critical, because students are given grades based on this evidence that carry an assumption of cognitive competence. As many critics have pointed out (e.g., Moll \& Greenberg, 1990), nonmainstream students are often labeled as cognitively deficient because of their lack of facility with the mediational means that produce the evidence for cognitive development in school settings.

Earlier I proposed that valid research is instructional. At this point I will propose that valid teaching represents inquiry-that is, research. Researchers teach through their mediation of student learning; teachers research through their mediation of student learning. This conception holds up only under the definition of validity that I have proposed, which is dependent on the particular conception of Vygotsky's (1978, 1934/1987) ZPD that I have outlined in this essay.

\section{The Validity of Luria's Conclusions}

I would like to conclude this discussion with an examination of the research of Vygotsky's student and collaborator Luria (1976), who headed a research team that studied the impact of broad societal change on the thinking of residents of remote villages and mountain pasturelands of Uzbekistan and Kirghizia in the 1930s. Luria argued that his study stands in contrast to what he calls "culturalogical" studies designed "to apply 'racial' theories to the data in order to prove the subjects' "inferiority"' (p. vi). Yet in spite of his belief that he did not characterize his research participants in a denigrating way, he also said that the people he studied

had lived for centuries in economic stagnation and illiteracy, their development hindered among other things by the religion of Islam. Only the radical restructuring of the economy, the rapid elimination of illiteracy, and the removal of the Moslem influence could achieve, over and above an expansion in world view, a genuine revolution in cognitive activity. (p. vi)

Luria's (1976) remarks reveal that he had a specific view of telos, one that emerged from the same Russian middle-class view espoused by Vygotsky (1934/ 1987 ) in valuing the development of speech-mediated scientific concepts as the ultimate form of cognitive maturity. Luria's means of testing these remote peasants' cognitive activity were distinctly Western, as were his criteria for judging mature thought. As the following examples will illustrate, the peasants shared 


\section{Smagorinsky}

neither the researcher's sense of telos nor his regard for specific mediational means. As a consequence, I believe, the research is not mediational and therefore of questionable validity (cf. Cole, 1985; Saxe, 1994).

In testing the participants' abilities in generalization and abstraction, for instance, Luria (1976) and his associates would give a person a series of items and ask him or her to organize them. To frame his presentation of data, Luria provided a developmental account predicated on the model of maturation typical of the children studied by Vygotsky (1934/1987) in his metropolitan laboratory:

The child has yet to develop a general unified principle of operation; hence, he cannot construct a general unified category. He will group together objects such as a large blue circle (color), a small blue triangle (form), a small green square (size), a small green cube (color), and so on. The group of objects that emerges reflects no unified concept but rather a complex of objects, each included on an individual basis. (Luria, 1976, p. 51)

Through analysis of this type, Luria claimed to be working with "the psychological elements governing such taxonomic cognition," through which a "reliance on society-wide criteria transforms graphic thinking processes into a scheme of semantic and logical operations in which words become the principal tool for abstraction and generalization" (p. 52). Luria's notions that cognition is "taxonomic" and that there existed "society-wide criteria" led him to judge the peasants as underdeveloped and, indeed, childlike, at least according to the developmental model he posited as optimal.

The following excerpt, for instance, typifies his many characterizations of the peasants as underdeveloped.

[Participants] replaced a theoretical task by a practical one: to reproduce the practical relationships among objects. This tendency became apparent early in the experimental session when subjects immediately began to evaluate objects in isolation and designate their functions ("this one" is needed for such-and-such a job, "that one" for another). They saw no need to compare and group objects in abstract terms and assign them to specific categories. Later on in the experiment many of the subjects were able to overcome this tendency. (Luria, 1976, p. 54)

Here, Luria (1976) appears to have used questionable means to investigate the culturally appropriate cognitive activity of his research participants, and therefore seems inattentive to the manner in which his data were socially constructed. First of all, he assumed that speech is the principal tool of mediation, a presumption that many cultural studies have begun to question (see, for instance, Philips' [1972] research on Warm Springs Indians in the American Southwest, for whom speech is not a primary mode of learning). Fundamentally, then, Luria contributed to the social construction of his data by assuming that speech was primary to development; he then used speech as the means through which to elicit his data, regardless of its appropriateness to the culture under study.

Luria's (1976) second contribution to the social construction of his data concerns the set of tasks presented to his participants. As he noted throughout his report, the peasants' lives (and, therefore, their thinking) were centered around situated, contextualized activity. Yet the tasks Luria presented to them were 
decontextualized problems such as those found in school. The means of assessment, therefore, were not likely to be responsive to the type of higher mental processes developed within the society and functional for its way of life. The problem Luria created through his use of inappropriate cultural tools was similar to the one Moll and Greenberg (1990) identified in their study of situated cognition in Mexican American communities and schools.

Luria (1976) contributed to the social construction of his data in a third crucial way, by eliciting responses from his participants in face-to-face social transactions. Here, for instance, is a segment from what he referred to as his "experimental protocols":

Subject: Rakmat., age thirty-nine, illiterate peasant from an outlying district; has seldom been in Fergana, never in any other city. He was shown drawings of the following: hammer-saw-log-hatchet.

[He said,] "They're all alike. I think all of them have to be here. See, if you're going to saw, you need a saw, and if you have to split something you need a hatchet. So they're all needed here."

Employs the principle of "necessity" to group objects in a practical situation.

We tried to explain the task by another, simpler example.

[We said,] Look, here you have three adults and one child. Now clearly the child doesn't belong in this group.

[He responded,] "Oh, but the boy must stay with the others! All three of them are working, you see, and if they have to keep running out to fetch things, they'll never get the job done, but the boy can do the running for them. ... The boy will learn; that'll be better, then they'll all be able to work well together."

Applies same principle of grouping.

[We said,] Look, here you have three wheels and a pair of pliers. Surely, the pliers and the wheels aren't alike in any way, are they?

"No, they all fit together. I know the pliers don't look like the wheels, but you'll need them if you have to tighten something in the wheels."

Again assigns objects functions in a practical situation.

[We said,] But you can use one word for the wheels that you can't for the pliers-Isn't that so?

[He responded,] "Yes, I know that, but you've got to have the pliers. You can lift iron with them and it's heavy, you know."

[We asked,] Still, isn't it true that you can't use the same word for both the wheels and the pliers?

"Of course you can't." (pp. 55-56)

The researcher continues questioning Rakmat in this fashion, seemingly incredulous at his inability to classify the objects in a manner consistent with the researcher's notion of appropriate grouping. At the same time, Rakmat appears to be resistant to the researcher's efforts to lead him to different responses. Luria concluded, "we had no luck getting these subjects to perform the abstract act of classification. Even when they grasped some similarity among various objects, they attached no particular importance to the fact" (p. 59). In this case, even with the researcher's great efforts to affect the data ("Still, isn't it true that . . . ?"), Rakmat persisted with his view of the problem, a condition that led Luria to state among his "principal facts derived from the tests" that Rakmat and others were not 


\section{Smagorinsky}

yet ready "to become part of a more advanced culture" (p. 79).

The cultural differences between Rakmat and the research team-and their concomitant different purposes in posing and responding to questions-no doubt account for the discontinuity of the interview. Intersubjectivity between researcher and participant appears to be a crucial factor in the social construction of data. It contributes to the degree to which researcher and participant grasp and build on one another's articulated thinking, share a sense of telos, and value the mediational means that enable people to achieve that sense of telos.

\section{Final Remarks}

I conclude this article with a lengthy discussion of Luria's (1976) work because it has become so widely cited in neo-Vygotskian research, and because it contains so many of the problems that I have discussed-problems often found in research conducted without consideration for the methodological implications of the ZPD. In the concluding paragraph of his monograph, Luria refers to the "backward and remote region" he has studied, a characterization that reveals his disposition to regard his own cognitive state as optimal and to judge those who are different as more childlike and less advanced. I would argue that this characterization came through inappropriate means that ignored the semiotic structure of the peasants' communicative environment. Luria's judgment of their cognition as undeveloped is a social construct made from a relative position that did not take into account the ZPDs that structured learning and development in the community under study.

Presumably, educational research is conducted to improve education. Assumptions of the neutrality of research procedures and the purity of research environments, however, may lead to spurious conclusions about the people who participate in research and to the development of inappropriate policies to remedy perceived educational problems. Researchers need to (a) acknowledge the social construction of the mediational tools provided to students during both training and assessment and (b) reflect on how their own implication in the research process affects teaching and learning and the evaluation of both. Our effort should not be to avoid participating in the construction of data, but to recognize and account for the ways in which we inevitably contribute to the shape our data take.

\section{Note}

This article is adapted from a paper presented at the International Conference on Lev Vygotsky and the Contemporary Human Sciences, September 5-8, 1994, Moscow. Participation in this conference was supported by a grant from the International Research and Exchanges Board, with funds provided by the U.S. Department of State (Title VIII). Support was also provided by the Graduate College and Department of Instructional Leadership and Academic Curriculum at the University of Oklahoma. None of these organizations is responsible for the views expressed. I am greatly indebted to the conference organizers for giving me the opportunity to develop this essay, and to all conference participants whose ideas are woven into it. In addition, many friends and colleagues provided helpful critiques of earlier versions of parts or all of this manuscript: Chuck Bazerman, Sally Beach, John Behrens, Betsy Burris, Don Cunningham, Anne DiPardo, Terri Roedel, Melanie Sperling, Gordon Wells, and the editors and reviewers of $R E R$, at whose behest I have addressed the knottiest issues examined in this article. Finally, the article has benefitted from many insights contrib- 
uted by participants in the XLCHC E-mail discussion network, who have made this project a truly collaborative effort.

\section{References}

Adair, J. G., Sharpe, D., \& Huynh, C. (1989). Hawthorne control procedures in educational experiments: A reconsideration of their use and effectiveness. Review of Educational Research, 59, 215-228.

American Psychiatric Association. (1994). Diagnostic and statistical manual of mental disorders (4th ed.). Washington, DC: Author.

American Psychological Association. (1983). Publication manual of the American Psychological Association (3rd ed.). Washington, DC: Author.

Bazerman, C. (1988). Shaping written knowledge: The genre and activity of the experimental article in science. Madison, WI: University of Wisconsin Press.

Behrens, J. T., \& Smith, M. L. (in press). Data and data analysis. In D. Berliner \& R. Calfee (Eds.), The handbook of educational psychology. New York: Macmillan.

Berger, P. L., \& Luckman, T. (1966). The social construction of reality: A treatise in the sociology of knowledge. New York: Doubleday.

Bloom, B. (Ed.). (1956). Taxonomy of educational objectives: The classification of educational goals (Handbook 1: Cognitive domain). New York: McKay.

Brodkey, L. (1992). Articulating poststructural theory in research on literacy. In R. Beach, J. L. Green, M. L. Kamil, \& T. Shanahan (Eds.), Multidisciplinary perspectives on literacy research (pp. 293-318). Urbana, IL: National Conference on Research in English and National Council of Teachers of English.

Brown, A. L., \& Palincsar, A. S. (1989). Guided, cooperative learning and individual knowledge acquisition. In L. Resnick (Ed.), Knowing, learning, and instruction: Essays in honor of Robert Glaser (pp. 393-451). Hillsdale, NJ: Erlbaum.

Cazden, C. B. (1979). Peekaboo as an instructional model: Discourse development at home and at school. Papers and Reports on Child Language Development, 17, 119.

Cazden, C. B. (in press). Selective traditions: Readings of Vygotsky in writing pedagogy. In D. Hicks (Ed.), Child discourse and social learning: An interdisciplinary perspective. Cambridge: Cambridge University Press.

Cohen, A. P. (1989). The symbolic construction of community. New York: Routledge.

Cole, M. (1985). The zone of proximal development: Where culture and cognition create each other. In J. V. Wertsch (Ed.), Culture, communication, and cognition: Vygotskian perspectives (pp. 146-161). New York: Cambridge University Press.

de Certeau, M. (1985). Practices of space. In M. Blonsky (Ed.), On signs (pp. 122-145). Baltimore, MD: The Johns Hopkins University Press.

Eco, U. (1985). How culture conditions the colours we see. In M. Blonsky (Ed.), On signs (pp. 157-175). Baltimore, MD: The Johns Hopkins University Press.

Berliner, D. C. (Ed.). (1992). Educational Researcher, 21(5), 5-17.

Foucault, M. (1972). The archaeology of knowledge and the discourse on language (A. M. Sheridan Smith, Trans.). New York: Pantheon.

Gardner, H. (1983). Frames of mind. New York: Basic Books.

Geertz, C. (1973). The interpretation of cultures. New York: Basic Books.

Goodman, Y. M., \& Goodman, K. S. (1990). Vygotsky in a whole-language perspective. In L. C. Moll (Ed.), Vygotsky and education: Instructional implications and applications of sociohistorical psychology (pp. 223-250). New York: Cambridge University Press.

Hanna, J. L. (1987). To dance is human: A theory of nonverbal communication. Chicago: University of Chicago Press.

Heath, S. B. (1991). The sense of being literate: Historical and cross-cultural features. 


\section{Smagorinsky}

In R. Barr, M. L. Kamil, P. Mosenthal, \& P. D. Pearson (Eds.), Handbook of reading research (Vol. 2, pp. 3-25). New York: Longman.

Hundeide, K. (1985). The tacit background of children's judgments. In J. V. Wertsch (Ed.), Culture, communication, and cognition: Vygotskian perspectives (pp. 306322). New York: Cambridge University Press.

John-Steiner, V. (1987). Notebooks of the mind: Explorations in thinking. New York: Harper \& Row.

John-Steiner, V. (1995). Cognitive pluralism: A sociocultural approach. Mind, Culture, and Activity, 2(1), 2-10.

Lave, J., Murtaugh, M., \& de la Rocha, O. (1984). The dialectic of arithmetic in grocery shopping. In B. Rogoff \& J. Lave (Eds.), Everyday cognition: Its development in social context (pp. 67-94). Cambridge, MA: Harvard University Press.

Lave, J., \& Wenger, E. (1991). Situated learning: Legitimate peripheral participation. New York: Cambridge University Press.

Lee, C. (1993). Signifying as a scaffold for literary interpretation: The pedagogical implications of an African American discourse genre (Research Rep. No. 26). Urbana, IL: National Council of Teachers of English.

Leont'ev, A. N. (1981). Problems of the development of mind. Moscow: Progress Publishers.

Luria, A. R. (1976). Cognitive development: Its cultural and social foundations (M. Cole, Ed.; M. Lopez-Morillas \& L. Solotaroff, Trans.). Cambridge, MA: Harvard University Press.

Marshall, J. D., Smagorinsky, P., \& Smith, M. W. (1995). The language of interpretation: Patterns of discourse in discussions of literature (Research Rep. No. 27). Urbana, IL: National Council of Teachers of English.

McCarthy, L. P., \& Gerring, J. P. (1994). Revising psychiatry's charter document DSMIV. Written Communication, 11(2), 147-192.

McCloskey, D. N. (1985). The rhetoric of economics. Madison, WI: University of Wisconsin Press.

McKerrow, K. K., \& McKerrow, J. E. (1991). Naturalistic misunderstanding of the Heisenberg uncertainty principle. Educational Researcher, 20(1), 17-20.

McLaren, P. (1992). Literacy research and the postmodern turn: Cautions from the margins. In R. Beach, J. L. Green, M. L. Kamil, \& T. Shanahan(Eds.), Multidisciplinary perspectives on literacy research (pp. 319-339). Urbana, IL: National Conference on Research in English and National Council of Teachers of English.

Moll, L. C. (1990). Introduction. In L. C. Moll (Ed.), Vygotsky and education: Instructional implications and applications of sociohistorical psychology (pp. 1-27). New York: Cambridge University Press.

Moll, L. C., \& Greenberg, J. B. (1990). Creating zones of possibilities: Combining social contexts for instruction. In L. C. Moll (Ed.), Vygotsky and education: Instructional implications and applications of sociohistorical psychology (pp. 319-348). New York: Cambridge University Press.

Newman, D., Griffin, P., \& Cole, M. (1989). The construction zone: Working for cognitive change in school. New York: Cambridge University Press.

Noddings, N. (1992). The challenge to care in schools: An alternative approach to education. New York: Teachers College Press.

Olson, D. R. (1977). From utterance to text: The bias of language in speech and writing. Harvard Educational Review, 47, 257-281.

Pea, R. D. (1993). Practices of distributed intelligence and designs for education. In G. Salomon (Ed.), Distributed cognitions: Psychological and educational considerations (pp. 47-87). New York: Cambridge University Press.

Philips, S. U. (1972). Participant structures and communicative competence: Warm 
Springs children in community and classroom. In C. B. Cazden, V. P. John, \& D. Hymes (Eds.), Functions of language in the classroom (pp. 370-394). New York: Teachers College Press.

Rogoff, B. (1990). Apprenticeship in thinking: Cognitive development in social context. New York: Oxford University Press.

Salomon, G. (Ed.). (1993). Distributed cognitions: Psychological and educational considerations. New York: Cambridge University Press.

Saxe, G. B. (1994). Studying cognitive development in sociocultural context: The development of a practice-based approach. Mind, Culture, and Activity, 1(3), 135157.

Schultz, J. J., Florio, S., \& Erickson, F. (1982). Where's the floor? Aspects of the cultural organization of social relationships in communication at home and in school. In P. Gilmore \& A. A. Glatthorn (Eds.), Children in and out of school: Ethnography and education (pp. 88-123). Washington, DC: Center for Applied Linguistics.

Smagorinsky, P. (1995). Constructing meaning in the disciplines: Reconceptualizing writing across the curriculum as composing across the curriculum. American Journal of Education, 103(2), 160-184.

Smagorinsky, P., \& Coppock, J. (1994). Cultural tools and the classroom context: An exploration of an artistic response to literature. Written Communication, 11(3), 283310.

Smagorinsky, P., \& Coppock, J. (in press-a). The reader, the text, the context: An exploration of a choreographed response to literature. JRB: A Journal of Literacy.

Smagorinsky, P., \& Coppock, J. (in press-b). Reading through the lines: An exploration of drama as a response to literature. Reading \& Writing Quarterly.

Smagorinsky, P., \& Fly, P. K. (1993). The social environment of the classroom: A Vygotskian perspective on small group process. Communication Education, 42(2), $159-171$.

Smagorinsky, P., \& Whiting, M. E. (1995). How English teachers get taught: Methods of teaching the methods class. Urbana, IL: Conference on English Education and National Council of Teachers of English.

Swanson-Owens, D., \& Newell, G. E. (1994). Using intervention protocols to study the effects of instructional scaffolding on writing and learning. In P. Smagorinsky (Ed.), Speaking about writing: Reflections on research methodology (pp. 141-162). Thousand Oaks, CA: Sage.

Tulviste, P. (1991). The cultural-historical development of verbal thinking. Commack, NY: Nova Science Publishers.

Tyler, R. (1949). Basic principles of curriculum and instruction. Chicago: University of Chicago Press.

Vygotsky, L. S. (1934). Myshlenie i rech': Psikhologicheskie issledovaniya. Moscow and Leningrad: Gosudarstvennoe Sotsial'no-Ekonomicheskio Izdatel'stvo.

Vygotsky, L. S. (1962). Thought and language. Cambridge, MA: MIT Press. (Original work published 1934)

Vygotsky, L. S. (1978). Mind in society: The development of higher psychological processes (M. Cole, V. John-Steiner, S. Scribner, \& E. Souberman, Eds.). Cambridge, MA: Harvard University Press.

Vygotsky, L. S. (1986). Thought and language (A. Kozulin, Ed. \& Trans.). Cambridge, MA: MIT Press. (Original work published 1934)

Vygotsky, L. S. (1987). Thinking and speech. In L. S. Vygotsky, Collected works (Vol. 1, pp. 39-285) (R. Rieber \& A. Carton, Eds; N. Minick, Trans.). New York: Plenum. (Original work published 1934)

Vygotsky, L. S., \& Luria, A. R. (1993). Studies on the history of behavior: Ape, primitive, and child (V. I. Golod \& J. E. Knox, Eds. \& Trans.). Hillsdale, NJ: Erlbaum. 


\section{Smagorinsky}

Wells, G. (1995). E-mail message, XLCHC, January 28.

Wertsch, J. V. (1985). Vygotsky and the social formation of mind. Cambridge, MA: Harvard University Press.

Wertsch, J. V. (1991). Voices of the mind: A sociocultural approach to mediated action. Cambridge, MA: Harvard University Press.

Wertsch, J. V. (1994). The primacy of mediated action in sociocultural studies. Mind, Culture, and Activity, 1(4), 202-208.

Wertsch, J. V. (1995). E-mail message, XLCHC, January 28.

Wong, E. D. (1995). Challenges confronting the researcher/teacher: Conflicts of purpose and conduct. Educational Researcher, 24(3), 22-28.

\section{Author}

PETER SMAGORINSKY is Associate Professor, College of Education, University of Oklahoma, 820 Van Vleet Oval, Norman, OK 73019-0260; smagor@aardvark.ucs.uoknor.edu. He specializes in defining and assessing classroom literacy.

Received August 15, 1994

Revision received March 25, 1995

Accepted April 11, 1995 